\title{
Prediction of hepatitis C burden in Canada
}

\author{
Shimian Zou MD PhD, Martin Tepper MD MHSc FRCPC, Susie El Saadany MMath/Stat PGD-Math
}

S Zou, M Tepper, S El Saadany. Prediction of hepatitis C burden in Canada. Can J Gastroenterol 2000;14(7):575-580. To assess the risk of hepatitis $\mathrm{C}$ in Canada and to predict the burden that this disease may pose to the Canadian society in the near future, expected numbers of persons at different stages of the disease currently and in the next decade were estimated by simulation using a published hepatitis $C$ natural history model with no treatment effect being applied. Based on the estimate of 240,000 persons who are currently infected with the hepatitis $\mathrm{C}$ virus in Canada, the simulation analysis demonstrated that the number of hepatitis C cirrhosis cases would likely increase by $92 \%$ from 1998 to the year 2008. It was also projected that the number of liver failures and hepatocellular carcinomas related to hepatitis $\mathrm{C}$ would increase by $126 \%$ and $102 \%$, respectively, in the next decade. The number of liver-related deaths associated with hepatitis $\mathrm{C}$ is expected to increase by $126 \%$ in 10 years. The medical and social care systems in Canada may not be ready to support these large increases. These results highlight the importance of both the control of disease progression of hepatitis $\mathrm{C}$ virus-infected persons and the primary prevention of hepatitis $\mathrm{C}$ infections in Canada.

Key Words: Computer simulation; Disease burden; Hepatitis C; Natural history

\section{Prévisions quant au poids de l'hépatite $\mathrm{C}$ au Canada}

RÉSUMÉ : Pour mesurer le risque associé à l'hépatite C au Canada et prédire le fardeau que cette maladie pourrait représenter pour la société canadienne dans un avenir rapproché, les nombres prévisibles de patients aux différents stades de la maladie à l'heure actuelle et au cours des dix prochaines années ont été estimés par simulation au moyen d'un modèle publié sur l'histoire naturelle de l'hépatite $\mathrm{C}$, sans effet thérapeutique appliqué. Sur la base d'une estimation selon laquelle 240000 personnes seraient actuellement infectées par le virus de l'hépatite $\mathrm{C}$ au Canada, l'analyse de simulation a démontré que le nombre de cas de cirrhose causés par l'hépatite $\mathrm{C}$ augmenterait de $92 \%$ entre 1998 et 2008. On a également projeté que le nombre d'insuffisances hépatiques et d'hépatocarcinomes lié à l'hépatite C allait augmenter de 126 et de $102 \%$ respectivement au cours de la décennie à venir. Le nombre de décès associés à l'hépatite $\mathrm{C}$ devrait augmenter de $126 \%$ au cours des dix prochaines années. Les systèmes de soins sociaux et médicaux canadiens ne sont peut-être pas prêts à réagir à d'aussi fortes augmentations. Ces résultats rappellent l'importance de ralentir l'évolution de la maladie chez les personnes qui ont contracté le virus de l'hépatite C et d'appliquer des mesures de prévention primaire contre l'infection par le virus de l'hépatite $\mathrm{C}$ au Canada.
$\mathrm{T}$ he discovery of the hepatitis C virus (HCV) in 1989 ended a period of intense international research efforts aimed at the elusive 'non-A, non-B' hepatitis virus (1). Development of serological tests for $\mathrm{HCV}$ infection has shown that this virus has been the primary etiological agent of parenterally transmitted non- $A$, non-B hepatitis and an important cause of acute and chronic hepatitis worldwide (2).

Hepatitis $\mathrm{C}$ is usually a subclinical infection, with only
$25 \%$ of patients with post-transfusion hepatitis developing jaundice (3). Clinically and histopathologically, it is similar to viral hepatitis caused by other agents (4).

The most important feature of hepatitis $\mathrm{C}$ is the high frequency $(75 \%$ to $85 \%$ ) with which acute disease progresses to chronic infection. Available studies of hepatitis $\mathrm{C}$ infections showed that the disease has a protracted course and that serious sequelae may not appear until decades after infection

Bloodborne Pathogens Division, Bureau of Infectious Diseases, Laboratory Centre for Disease Control, Ottawa, Ontario

Correspondence: Dr S Zou, Postal Locator 0601E2, Bloodborne Pathogens Division, Bureau of Infectious Diseases, Laboratory Centre for Disease

Control, Ottawa, Ontario K1A OL2. Telephone 613-946-8819, fax 613-952-6668, e-mail shimian_zou@hc-sc.gc.ca

Received for publication December 23, 1999. Accepted April 19, 2000 
TABLE 1

Age distribution of hepatitis $C$ cases and time of exposure for each age cohort

\begin{tabular}{lccccc}
\hline $\begin{array}{l}\text { Age } \\
\text { group } \\
\text { (years) }\end{array}$ & $\begin{array}{c}\text { Age } \\
\text { distribution } \\
\text { of identified } \\
\text { cases (\%) }\end{array}$ & $\begin{array}{c}\text { Mean age } \\
\text { (years) }\end{array}$ & $\begin{array}{c}\text { Projected } \\
\text { number of } \\
\text { cases }\end{array}$ & $\begin{array}{c}\text { Time of } \\
\text { exposure }\end{array}$ & $\begin{array}{c}\text { Age of } \\
\text { infection } \\
\text { (years) }\end{array}$ \\
\hline $0-19$ & 3.5 & 10 & 6651 & Recent & 10 \\
$20-29$ & 12.5 & 26 & 23,978 & Recent & 26 \\
$30-39$ & 35.6 & 35 & 68,259 & $\begin{array}{c}5 \text { years ago } \\
\text { 16 years }\end{array}$ & 30 \\
$40-59$ & 43.1 & 46 & 82,786 & 30 \\
& 5.4 & 70 & 10,326 & $\begin{array}{c}\text { ago } \\
\text { 20 years } \\
\text { ago }\end{array}$ & 50 \\
60 & 100.0 & 40 & 192,000 & & \\
Total & & & & & \\
\hline
\end{tabular}

(5). Therefore, infections acquired in previous decades have significant effects on the current health of Canadians and the health care system of Canada.

In this report, hepatitis $\mathrm{C}$ burden in Canada for the near future is projected based on the estimation of the current infection level in Canada (6), and knowledge of the clinical spectrum and natural history of hepatitis C. The primary goal was to generate relatively unrefined point estimates to give a frame of reference for the current and projected burden.

\section{SUBJECTS AND METHODS}

To predict the burden of hepatitis $\mathrm{C}$, one needs to know the occurrence of the disease in the population, when the infection occurred and the progression or natural history of the disease. Because it has been difficult to identify new infections other than for a portion of transfusion-associated cases, no reliable incidence data in the general Canadian population are available for the assessment of risk level of the disease. As a result, an indirect approach was taken. A prevalence estimate of hepatitis $\mathrm{C}$ infections in the Canadian population, based on available data from surveillance and studies that were carried out in this country, was used as the basis for the present projection. Additional epidemiological data were then reviewed and used to determine the possible time of exposure for infected persons. Further, information about the natural history of the disease and progression probabilities of the disease to different stages were applied to the pool of $\mathrm{HCV}$-infected persons to calculate the expected numbers of cases who would be at different stages of the disease in the years to come.

Because new infections will likely not have a major impact on the disease burden in the near future because of the overall slow progression of the disease, prediction of hepatitis $\mathrm{C}$ burden in Canada that is reported here was made solely according to the estimate of the number of persons who are currently infected with HCV in Canada (the prevalence estimate).

Estimation of hepatitis $\mathrm{C}$ prevalence in Canada: Remis and colleagues (6), on reviewing the available data, estimated
TABLE 2

Assumptions used in the reported simulation

1. Number of prevalent cases of chronic hepatitis $\mathrm{C}$ in Canada: 192,000

2. Number of incident cases of hepatitis $C$ in Canada included in the simulation: nil

3. The age distribution of the 192,000 prevalent chronic cases: represented by remotely acquired hepatitis $C$ cases identified from the enhanced surveillance that was carried out in four health regions in Canada in 1998 to 1999 (LCDC, unpublished data)

4. The approximate time of exposure for each age group: estimated according to available epidemiological data (see Table 1)

5. Progression of these hepatitis $C$ cases to different stages of the disease: as specified in the SPEARS model (from reference 12, some items of the model are either combined or omitted here to simplify the description)

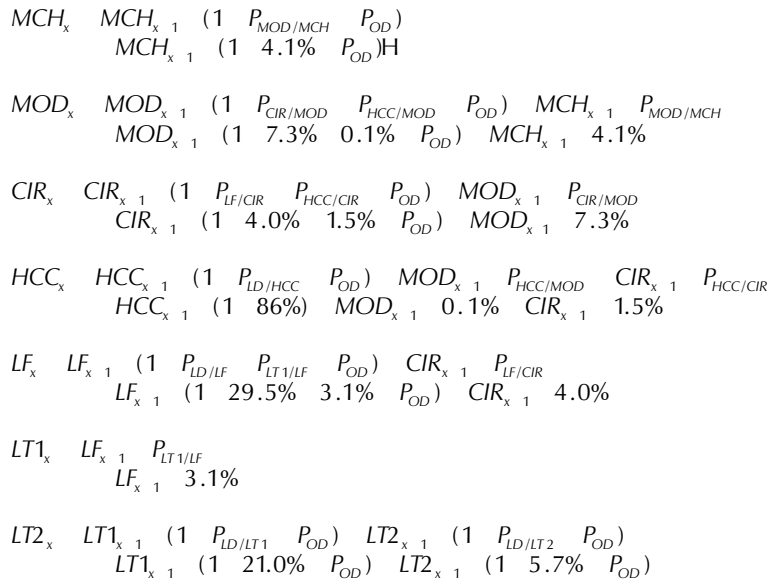

$L T_{x} \quad L T 1_{x} \quad L T 2_{x}$

where $\mathrm{x}$ is for a given year, $\mathrm{x}-1$ is for the previous year of a given year, $P_{O D}$ is the annual age-specific death rate of the general population and $\mathrm{P}_{\mathrm{MOD} / \mathrm{MCH}}$ is the annual progression probability to MOD from $\mathrm{MCH}$.

6. The mean age minus the average time of exposure is the starting age for each age group in the model

7. All cases started as mild chronic hepatitis and progressed to more severe stages of the disease as stated in assumption 5

8. All cases subject to the age-specific mortality in the general population

CIR Cirrhosis; HCC Hepatocellular carcinoma; LCDC Laboratory Centre for Disease Control; LD Liver death; LF Liver failure; LT Liver transplantation; LT1 Liver transplantation, first year; LT2 Liver transplantation, subsequent years; $M C H$ Mild chronic hepatitis; $M O D$ Moderate chronic hepatitis; OD Other death - age dependent; P Annual progression probability; SPEARS Schering-Plough Pharmaco Economic Analysis Review System

that the prevalence of anti-HCV positivity in Canada may be $0.8 \%$ ( $0.68 \%$ to $0.94 \%)$, or $240,000(210,000$ to 275,000$)$ persons. It was decided that this estimate of hepatitis $\mathrm{C}$ prevalence would be used as the basis for the prediction of hepatitis $\mathrm{C}$ burden in the near future in Canada. Because the natural history model that was used in this analysis was for chronic hepatitis $\mathrm{C}$, the number of prevalent chronic hepatitis $\mathrm{C}$ cases was determined based on the hepatitis $\mathrm{C}$ prevalence estimate of 240,000 . According to research results 
TABLE 3

Estimated number of cases of different stages of hepatitis C, 1998 and 2008*

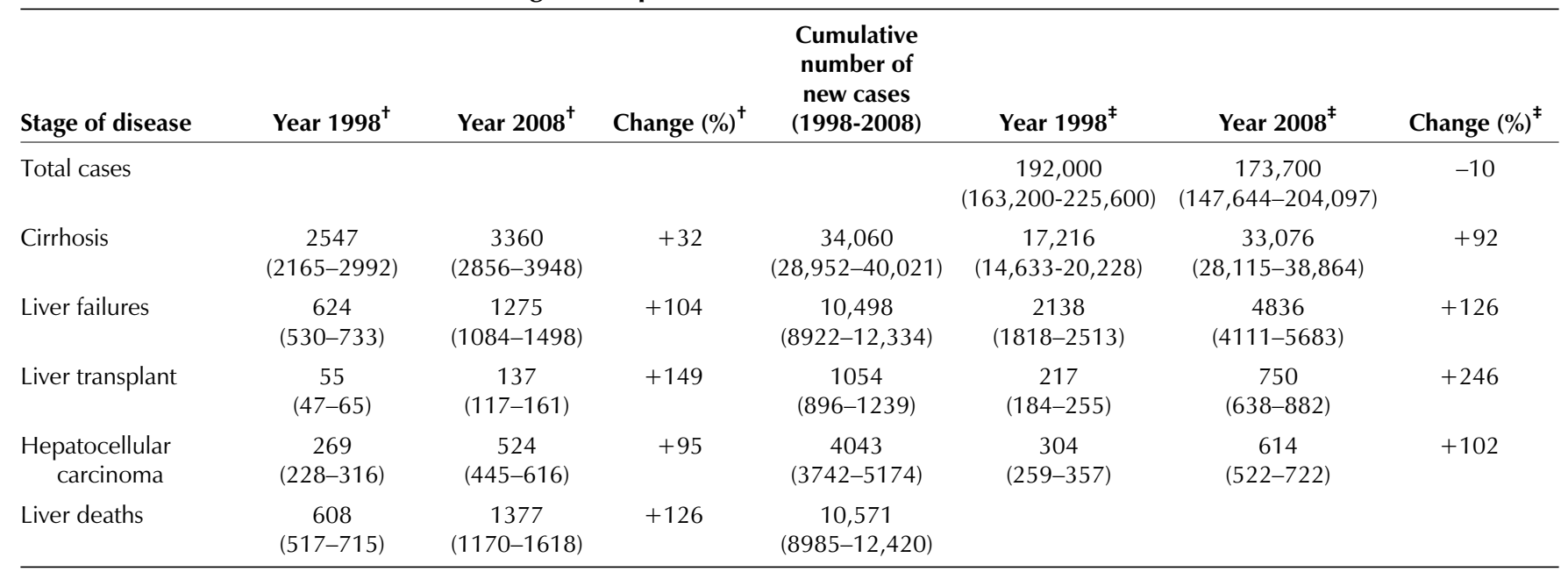

The numbers in brackets are the ranges obtained when the lower and upper limits of the prevalence estimate for hepatitis C (240,000) were used in the modelling. *With no treatment effect being applied and no newly acquired infections being included; ${ }^{+}$Annual incident cases, ie, cases who would enter into the indicated stage of the sequelae in the specific year; ${ }^{\ddagger}$ Annual prevalent cases, ie, cases who would be at the indicated stage of the sequelae during the specific year

available, hepatitis $\mathrm{C}$ viral RNA could be detected in approximately $80 \%$ of hepatitis $\mathrm{C}$ infections (7-9). Consequently, $80 \%$ of the 240,000 , or $192,000 \mathrm{HCV}$-infected persons, were assumed to have prevalent chronic hepatitis $\mathrm{C}$ infections.

Determination of time of hepatitis $\mathrm{C}$ infection: To predict the hepatitis $C$ burden based on the prevalence estimate, the time of exposure needs to be determined for the 192,000 chronically infected persons. First, age distribution was determined for this group. In collaboration with health departments in Edmonton and Calgary, Alberta, Winnipeg, Manitoba and Ottawa, Ontario, the Laboratory Centre for Disease Control (LCDC) carried out an enhanced surveillance project for hepatitis B and hepatitis C. The age distribution of the 1097 identified remotely acquired hepatitis $C$ cases (LCDC, unpublished data) was assumed to represent the total hepatitis $\mathrm{C}$ cases currently in Canada.

Next, average intervals from infection to identification were derived for each age group of cases from review of epidemiological studies of hepatitis C, both in Canada and from other countries. It was estimated by Remis and colleagues (6) that, on average, the currently surviving post-transfusion hepatitis $\mathrm{C}$ cases in Canada were infected approximately 20 years ago. The surveillance of four sentinel counties conducted by the Centers for Disease Control and Prevention indicated that individuals in different age groups acquired hepatitis $\mathrm{C}$ through different transmission routes (10). For the group 15 to 44 years of age, $59.8 \%$ of those with known risk factor information reported parenteral drug use during 1982 to 1985 , and $76.4 \%$ of those with known risk factor information reported parenteral drug use during 1986 to 1988 . However, for the group older than 44 years of age, $89.8 \%$ of those with known risk factor information reported blood transfusion during 1982 to 1985 , and $74.2 \%$ of those with known risk factor information reported blood transfusions during 1986 to 1988. According to a large French study (11), patients with hepatitis $C$ were infected at about 30 years of age on average and were diagnosed within approximately 10 years. Injection drug use was mainly associated with younger age groups ( $30.7 \pm 5.5$ years), whereas blood transfusion was involved in hepatitis $\mathrm{C}$ infections mostly in older age groups (48.9 \pm 14.7 years). The French study also showed a longer interval between infection and diagnosis for post-transfusion hepatitis $\mathrm{C}$ than for hepatitis $\mathrm{C}$ associated with injection drug use (11). Consequently, it was assumed that among current hepatitis $\mathrm{C}$ cases in Canada, those in the age groups 30 to 39 years (mean age 35 years) and 40 to 59 years (mean age 46 years) were infected when they were age 30 years (likely through injection drug use), resulting in an average interval from infection to present time of five years and 16 years, respectively. Those aged 60 years and older (mean age 70 years) were assumed to have been infected 20 years ago, at age 50 years (likely through blood transfusion); those of age 0 to 19 years or 20 to 29 years were assumed to have new infections. Most of the hepatitis $\mathrm{C}$ cases in the group aged 0 to 29 years were 15 to 29 years of age, a high proportion of whom were likely infected via injection drug use and were expected to have a shorter history; a certain percentage of these patients may have been infected several years ago, but this variation should not have a significant impact on the prediction here because the total number of cases in the group 0 to 29 years of age accounted for less than $20 \%$ of all cases.

Finally, combination of the approximated age distribution with the derived intervals from infection to identification gave rise to estimated age cohorts of exposure that were assumed to represent the overall exposure profile of persons currently infected with $\mathrm{HCV}$ in Canada. The derived number of hepatitis $\mathrm{C}$ cases for each age group and the corresponding age of exposure are shown in Table 1. 
Modelling of natural history of hepatitis C: Natural history models were recently established to assess the cost effectiveness of interferon treatment $(12,13)$. One such model, the Schering-Plough Pharmaco Economic Analysis Review System (SPEARS) model, was made available to the authors of this report through Schering Canada. Although supported by Schering, the model was developed by a group of independent investigators based on published research results and the Markov simulation (12). This model was used to perform the prediction reported here by simulating the transition and outcome of currently infected persons.

In the SPEARS model, the annual progression probabilities from mild chronic hepatitis to moderate chronic hepatitis, from moderate chronic hepatitis to cirrhosis and to hepatocellular carcinoma (HCC), and from cirrhosis to HCC were set at $4.1 \%, 7.3 \%, 0.1 \%$ and $1.5 \%$, respectively. According to the model, the annual progression probabilities from cirrhosis to decompensated liver diseases (liver failure) is $4 \%$ and the death rate for decompensated cases is $29.5 \%$. Of those reaching the decompensated liver disease stage, $3.1 \%$ were assumed to receive transplantation per year; $21 \%$ of the first year liver transplant recipients and $5.7 \%$ of liver transplant recipients after the first year would die annually. Each year, $0.1 \%$ of moderate hepatitis cases and $1.5 \%$ of cirrhotic cases would develop HCC. Table 2 summarizes the stages of the disease that are covered in the SPEARS model, the progression probabilities and the model assumptions.

Basically, the total numbers of patients at different stages of hepatitis $\mathrm{C}$ currently and in the near future were predicted by applying those disease progression probabilities to hepatitis $\mathrm{C}$ cases that occurred in Canada. For example, mild chronic hepatitis $\mathrm{C}$ progresses to moderate hepatitis $\mathrm{C}$ at an annual probability of $4.1 \%$. The expected number of mild chronic hepatitis cases in a given year is the number in the previous year minus the probability of death (agedependent) and $4.1 \%$ of progression to moderate chronic hepatitis.

In simulation, incorporation of the number of hepatitis $\mathrm{C}$ infections for each age cohort of exposure into the SPEARS model and combination of results for each age group gave rise to the total numbers of patients at different stages of hepatitis $\mathrm{C}$ currently and in the next decade. For example, for those in the age group 30 to 39 years who were infected at 30 years of age, the SPEARS model gave the proportion of cases at each disease stage at five years after infection (current status) and in each of the following years. Multiplication of those proportions by the total number of cases in this age group (Table 1) gave the estimated number of cases at different stages of the disease in different years after infection.

\section{RESULTS}

The expected burden of hepatitis $\mathrm{C}$ infection in 1998 and in the next decade was modelled, with no treatment effect being applied and no incident cases being included. Table 3 shows the estimated numbers of hepatitis $\mathrm{C}$ cases at different stages of the disease in Canada for 1998 and 2008. The numbers in brackets are the ranges obtained when the lower and upper limits of the prevalence estimate for hepatitis C $(240,000)$ were used in the modelling. Shown in the second, third and fourth columns are the estimated numbers of incident cases of different sequelae in 1998 and in 2008, and the percentage changes during the 10 -year period. For example, it was estimated that 2547 cases of hepatitis $C$ would become cirrhotic during 1998, whereas in 2008, that number was expected to reach 3360 , with an increase of $32 \%$. The number of liver deaths was estimated at 608 in 1998 and at 1377 in 2008 , with an increase of $126 \%$. The fifth column shows the cumulative numbers of incident cases of different sequelae from 1998 to 2008. It should be noted, however, that the number of liver transplantations was modelled based on the assumption that $3.1 \%$ of patients with liver failure would receive liver transplants annually.

Shown in the last three columns of Table 3 are the estimated numbers of prevalent cases of different sequelae in 1998 and in 2008, and the percentage changes during the 10 -year period. These prevalent cases are those who would be at the indicated stage of the natural history of the disease in a given year, some of whom would have been at the indicated stage before the specific year but would remain at the same stage in the specific year and some of whom would enter into the indicated stage from a less severe stage in the specific year. For example, in the year 2008, there could be as many as 33,076 hepatitis $C$ cases at the cirrhotic stage and 614 cases of HCC caused by hepatitis C in Canada. During the period from 1998 to 2008, the number of prevalent cirrhosis cases, prevalent liver failures, prevalent liver transplantations and prevalent HCC is expected to increase by $92 \%, 126 \%, 246 \%$ and $102 \%$, respectively. Again, the number of liver transplantations was derived with an assumed $3.1 \%$ liver transplantation rate for liver failure patients and an annual death rate of $21 \%$ or $5.7 \%$ for liver transplant recipients during the first year or thereafter, respectively.

To assess the impact of certain assumptions in the simulation process (Table 2), variations of those assumptions were incorporated into the model and results were compared with those presented above. First, the age distribution of chronic hepatitis $\mathrm{C}$ cases was modified to assign more cases to younger age groups, based on the reasoning that the chronic hepatitis $\mathrm{C}$ cases identified through the enhanced surveillance might be overly represented by older age groups. When the age group distribution derived from the report of Remis et al (6) was used in the model, the number of prevalent cases of cirrhosis, liver failure, liver transplantation and HCC were 14,232, 1740, 182 and 238, respectively, for 1998 and 30,236, 4233, 593 and 563, respectively, for 2008. Similarly, the incident cases of cirrhosis, liver failure, liver transplantation, HCC and liver death were 2259, 511, 45, 223 and 475, respectively, for 1998 and 3333, 1156, 117, 479 and 1223 , respectively, for 2008 . The corresponding percentage changes from 1998 to 2008 were 112, 143, 226 and 137, respectively, for prevalent cases and 48, 126, 163, 115 and 157 , 
respectively, for incident cases. These results were very similar to the data in Table 3.

Furthermore, the time of exposure was also modified to analyze the impact. It was shown that change in time of exposure in younger age groups did not have a significant impact, although in the 60 years and older age group the impact was more obvious. However, the number of initial chronic cases in this age group was relatively small (5.4\%), and the overall impact on the whole hepatitis C population was limited (data not shown).

\section{DISCUSSION}

It should be pointed out that the estimations made above were based on limited data available and that some of the data were from studies in other countries. Although much effort has been made to provide the appropriate calculations, these estimations should be viewed and used with caution, especially for individual hepatitis C cases. Nevertheless, these estimations may provide a basis for further risk assessment of hepatitis $\mathrm{C}$ infections in this country and aid in the risk management of the disease.

Overall, the prevalence estimate for hepatitis $\mathrm{C}$ infection in Canada made by Remis and colleagues (6), while not a direct measurement, is thought to be reasonable. Approximately $0.8 \%$ or 240,000 of Canadians are anti-HCV positive.

Based on the above estimate and available data on survival and clinical spectrum of the disease that are incorporated in the SPEARS model, the burden of hepatitis $\mathrm{C}$ and its changing pattern were projected for the next 10 years. Comparison of the simulation results for 1998 with the statistics available indicates that the projected hepatitis C burden may not be too different from the actual situation. According to vital statistics from Statistics Canada, it was estimated that 1056 deaths were caused by hepatitis $\mathrm{C}$ in 1996 in Canada (LCDC, unpublished data), which is higher but generally consistent with the result from the simulation analysis described here, ie, 608 liver deaths caused by hepatitis C in 1998. The Centers for Disease Control and Prevention estimated that there are currently 2,700,000 chronically infected hepatitis $\mathrm{C}$ cases in the United States and that 8000 to 10,000 deaths occur due to this disease annually $(9,14)$. If the proportion $(9,0002,700,000=0.003)$ is applied to the estimated 192,000 chronic hepatitis C cases in Canada, 640 hepatitis $\mathrm{C}$ deaths are expected each year, which is close to the projected number of liver deaths (608) for 1998. The vital statistics from Statistics Canada also showed that 419 deaths from HCC occurred in 1996 (LCDC, unpublished data). Considering that hepatitis $\mathrm{C}$ is one of the major causes of this cancer and that some HCC cases can be treated by transplantation and other means, the number of HCC cases projected for 1998 (269) may not be unreasonable.

Statistics from the Canadian Organ Replacement Register (CORR) showed that 340 single organ liver transplantations were performed in 1997, of which seven recipients had acute hepatic failure caused by hepatitis $\mathrm{C}$ and 64 recipients had chronic hepatic failure caused by hepatitis C (15). The number of liver transplantations predicted from this work, 55, is close to the actual statistics. According to CORR, 2735 liver transplantations were performed in Canada from 1981 to 1997, of which 67\% (1832) of patients were alive on December 31, 1997 (15). If the proportion of liver transplantations performed due to hepatitis C, $20.9 \%$ ( 71 of 340 ), is applied to those $67 \%$, there would be $383 \mathrm{HCV}$-infected liver transplant recipients surviving on December 31, 1997. The number of prevalent HCV-infected liver transplant recipients predicted from this work for 1998 (217) is roughly consistent with the CORR data.

There are very limited data about the number of hepatitis $\mathrm{C}$ cases at different stages of the disease that can be used to assess the estimates derived from this work. Hospital morbidity data from Statistics Canada are not suitable because such data count discharges not individual cases, do not separate specific causes of liver morbidity (eg, cirrhosis as opposed to other chronic liver disease; hepatitis $\mathrm{C}$ from other etiologies) and the most recent data are from 1993/94 (16).

Recently, Davis et al (17) presented their work on the prediction of future health care burden from hepatitis $\mathrm{C}$ in the United States. They used the same progression probabilities (natural history model for chronic hepatitis C [12]) as in the simulation process described here but with a slightly different simulation approach. They first estimated the hepatitis $\mathrm{C}$ incidence in the United States based on data from the Centers for Disease Control and Prevention. Afterwards, they extrapolated back, using age of acquisition and ageadjusted mortality to arrive at a figure roughly comparable with the 3.9 million prevalent cases in 1993. These incidence estimates were then incorporated with the disease natural history model to derive the health care burden prediction (GL Davis, personal communication). Because no data were available in Canada to support a reasonably accurate estimation for hepatitis $\mathrm{C}$ incidence, the prevalence estimate generated by Remis et al (6) was used instead as the basis for the simulation exercise presented here. Another difference between the work of Davis et al (17) and ours is that they assumed a zero progression for $30 \%$ of hepatitis $\mathrm{C}$ cases who have normal alanine aminotransferase levels, but we applied the natural history model to $80 \%$ of the 240,000 prevalent cases, or 192,000 prevalent chronic hepatitis C cases. However, this difference should not affect the percentage changes from 1998 to 2008, which is the principal message of the present study. Davis et al (17) predicted that, by the year 2008, the continued maturation of current cases of chronic hepatitis $\mathrm{C}$ would result in a $61 \%$ increase in cirrhosis, $279 \%$ increase in decompensated patients, $68 \%$ increase in HCC, $528 \%$ increase in the need for liver transplants and a $223 \%$ increase in liver-related deaths compared with those of 1998. Our estimates are broadly consistent with these predictions.

It should be noted that the SPEARS model was developed a few years ago and that certain aspects of the model may have been modified to reflect different opinions and possibly new developments. For example, certain progression probabilities may be somewhat higher or lower according to new data available. The rate of liver transplantations 
for liver failure patients may vary due to the availability of organs in different countries and in different years. Further, sensitivity analysis was not performed for the assumptions in the model. As more research data become available about the progression and natural history of hepatitis $\mathrm{C}$, the predictions obtained here may need to be revisited.

The occurrence of new hepatitis $\mathrm{C}$ infections and the impact of treatment were not incorporated into the simulation analysis because of the following considerations. First, there are a lack of reliable national incidence data for hepatitis $\mathrm{C}$ in Canada. The LCDC has been working with several sentinel health regions trying to bridge this gap. Second, the area of treatment for hepatitis $\mathrm{C}$ is progressing very rapidly, but it may be more appropriate to model the impact at a later date when the treatment formula is standardized and widely accepted in Canada.

Nevertheless, it is safe to predict that there will be large increases in morbid and mortal events related to the natural history maturation of the 192,000 chronically infected Ca-

\section{REFERENCES}

1. Choo Q-L, Kuo G, Weiner AJ, Overby LR, Bradley DW, Houghton $\mathrm{M}$. Isolation of a cDNA clone derived from a blood-borne non-A, non-B viral hepatitis genome. Science 1989;244:359-62.

2. Alter MJ. Epidemiology of hepatitis $C$ in the West. Semin Liver Dis 1995;15:5-14.

3. Dienstag JL. Non-A, non-B hepatitis. I: recognition, epidemiology, and clinical feature. Gastroenterology 1983;85:439-62.

4. Goodman ZD, Ishak KG. Histopathology of hepatitis $\mathrm{C}$ virus infection. Semin Liver Dis 1995;15:70-81.

5. Sharara AI, Hunt CM, Hamilton JD. Hepatitis C. Ann Intern Med 1996;125:658-68

6. Remis R, Hogg R, Krahn MD, Preiksaitis JK, Sherman M. Estimating the number of blood transfusion recipients infected by hepatitis $\mathrm{C}$ virus in Canada, 1960-85 and 1990-92. Report to Health Canada. June 22, 1998.

7. Rabindra RK, Tepper M, El Saadany S, Gully PR. Distribution of hepatitis $\mathrm{C}$ virus genotypes in Canada: results from the LCDC sentinel health unit surveillance system. Can J Infect Dis 1999;10:53-6.

8. Caudai C, Padula MG, Bastianoni I, et al. Antibody testing and RTPCR results in hepatitis $\mathrm{C}$ virus (HCV) infection: HCV-RNA detection in PBMC of plasma viremia-negative $\mathrm{HCV}$-seropositive persons. Infection 1998;26:151-4.

9. Alter MJ, Kruszou-Moran D, Nainan OV, et al. The prevalence of nadians. It is suspected that the medical and social care systems in Canada are not ready to support these large increases.

Furthermore, an increase in new infections caused by transmission through routes other than blood transfusion, such as needles or syringe sharing among injection drug users, although not incorporated into this analysis, would certainly add extra burden to the health care and social systems in the decades to come. Prevention and control of hepatitis $\mathrm{C}$ transmission through these routes as well as continuous screening and monitoring of the blood transfusion services cannot be overemphasized.

ACKNOWLEDGEMENT: The SPEARS model was provided by Schering Canada. Useful comments and suggestions were received from colleagues both within and outside of the LCDC, in particular, Dr Robert Remis of the University of Toronto and Dr John Spika of the LCDC; their support of this work is appreciated.

hepatitis C virus infection in the United States, 1988 through 1994. N Engl J Med 1999;341:556-62.

10. Alter MJ, Hadler SC, Judson FN, et al. Risk factors for acute non-A, non- $B$ hepatitis in the United States and association with hepatitis $C$ virus infection. JAMA 1990;264:2231-5.

11. Roudot-Thoraval F, Bastie A, Pawlotsky J-M, et al. Epidemiological factors affecting the severity of hepatitis $\mathrm{C}$ virus-related liver disease: a French study of 6,664 patients. Hepatology 1997;26:485-90.

12. Bennett WG, Inoue Y, Beck JR, Wong JB, Pauker SG, Davis GL. Estimates of the cost-effectiveness of a single course of interferonalpha2b in patients with histologically mild chronic hepatitis $\mathrm{C}$. Ann Intern Med 1997;127:855-65.

13. Kim WR, Poterucha JJ, Hermans JE, et al. Cost-effectiveness of 6 and 12 months of interferon-alpha therapy for chronic hepatitis C. Ann Intern Med 1997;127:866-74.

14. Alter MJ, Mast EE, Moyer LA, Margolis HS. Hepatitis C. Infect Dis Clin North Am 1998;12:13-26.

15. Canadian Organ Replacement Register 1999 Report. Ottawa: Canadian Institute for Health Information, 1999.

16. Hospital Morbidity and Surgical Procedures 1993-94. Ottawa: Statistics Canada, 1996:44.

17. Davis GL, Albright GE, Cook S, Rosenberg D. Projecting the future health care burden from hepatitis $\mathrm{C}$ in the United States. Hepatology 1998;28:390A. (Abst) 


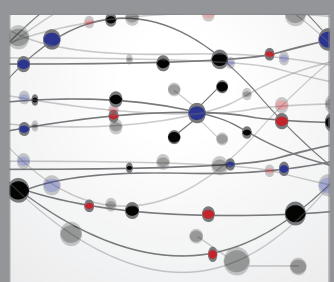

The Scientific World Journal
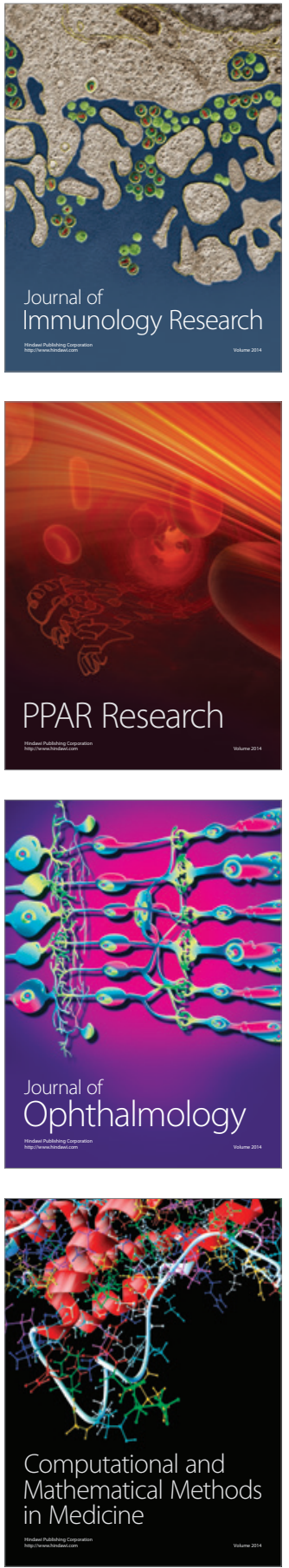

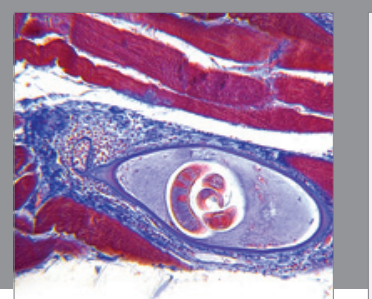

Gastroenterology Research and Practice

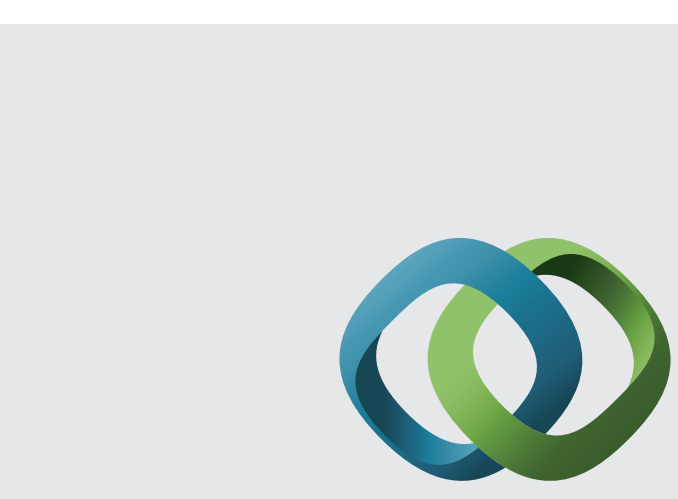

\section{Hindawi}

Submit your manuscripts at

http://www.hindawi.com
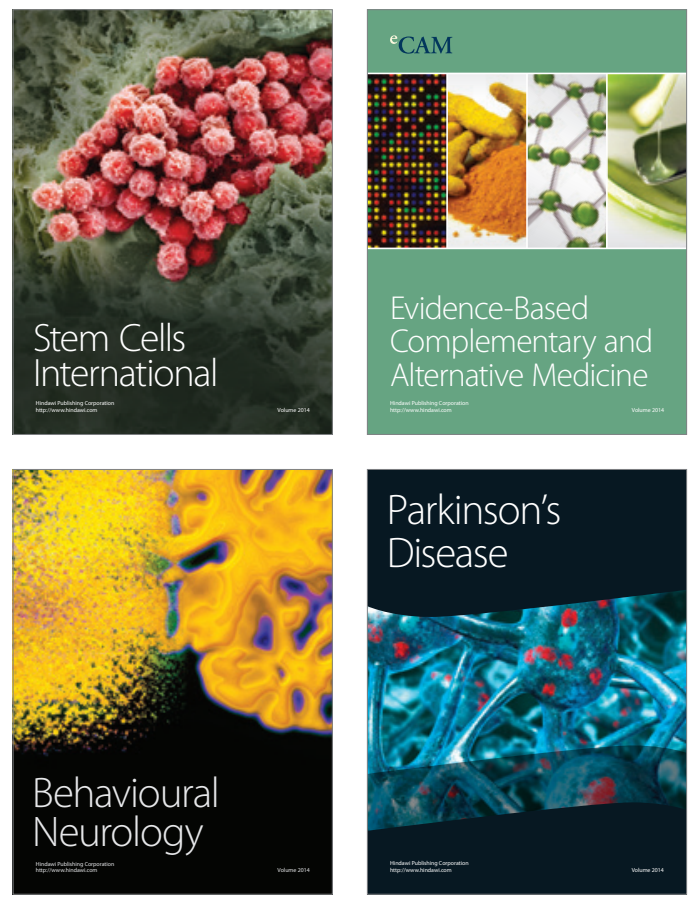
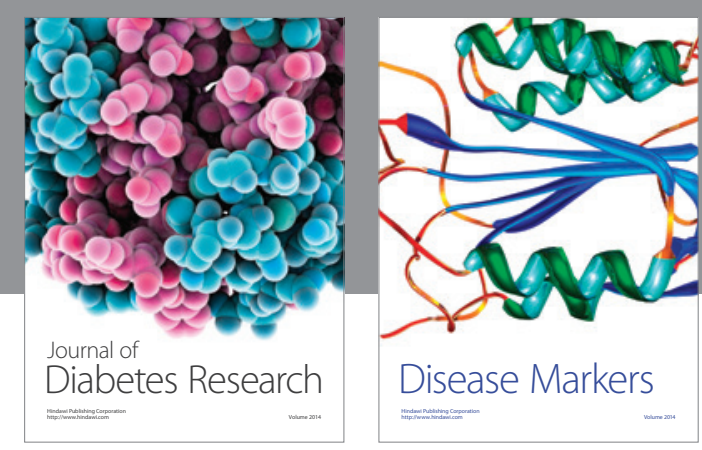

Disease Markers
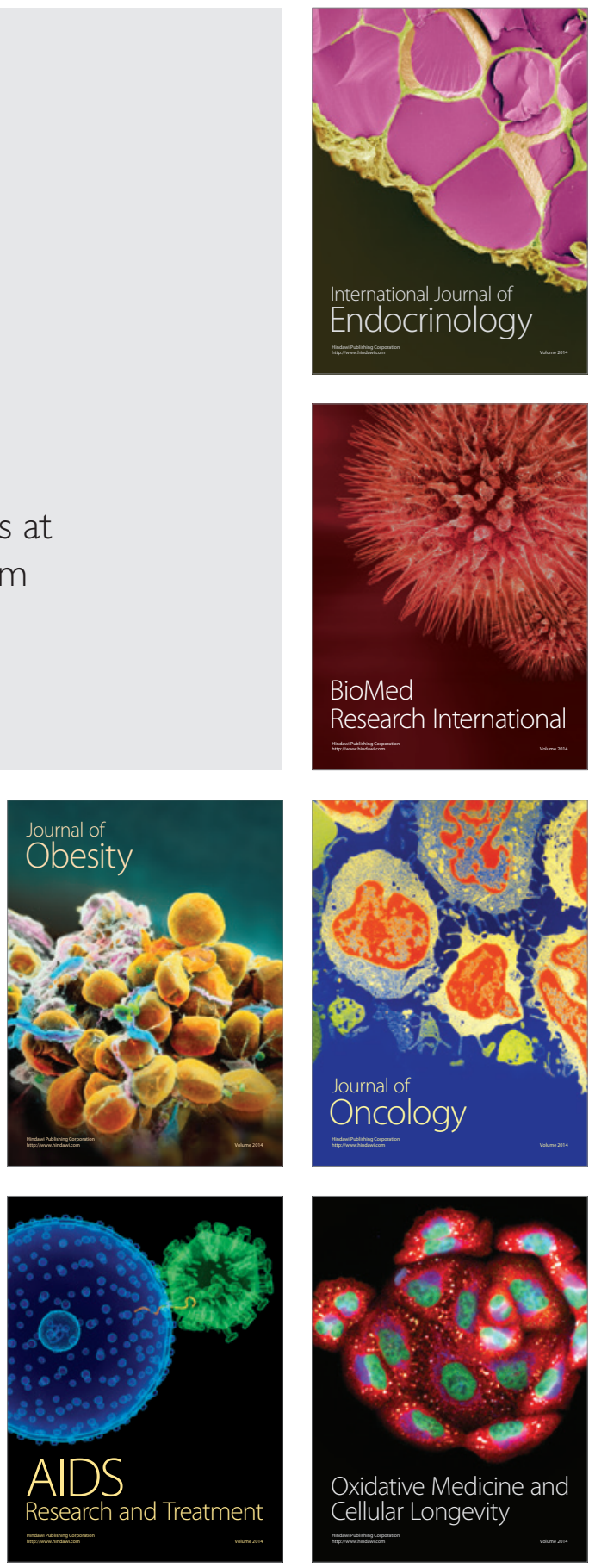